\title{
e-Tutor: A Multilingual Open Educational Resource for Faculty Development to Teach Online
}

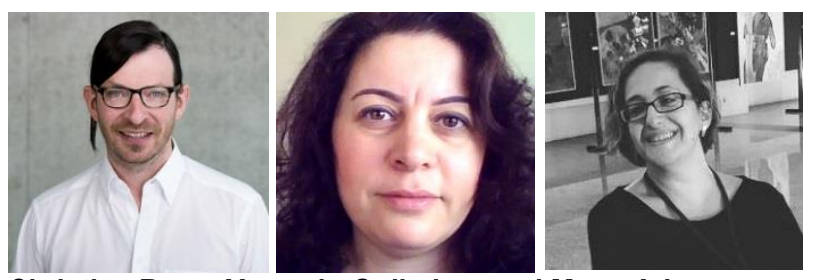

Christian Rapp, Yasemin Gülbahar, and Muge Adnan

Zurich University of Applied Sciences, Switzerland, Ankara University, Turkey, Muğla Sıtkı Koçman University, Turkey

\begin{abstract}
The situation in Ukraine poses severe problems to the higher education system and to students in Eastern Ukraine. Many students and academicians had been compelled to leave their university buildings and move westwards. Hence, they are forced to substitute face-to-face teaching with distance learning, often on a large scale, but within a short span of time and with limited resources. While technical/technological infrastructure often exists, know-how about conducting online teaching and respective faculty development is often found to be lacking. Within the framework of a project funded by the Swiss National Science Foundation (SNSF), a faculty development program developed in Turkey as an Open Educational Resource (e-Tutor) was adopted in three languages (English, Ukrainian, and Russian) to support qualifying university staff in teaching online. e-Tutor comprises of 14 modules, each with various content, covering different aspects of online teaching. In the following note, we briefly present the program along with the context, target group/aims, concept, genesis, initial experiences, and further development.
\end{abstract}

Keywords: E-learning, distance education, online teaching, staff development, faculty development

\section{Introduction}

The current situation in Ukraine poses severe problems to the higher education (HE) system and to the students of Eastern Ukraine in particular. Many had been compelled to leave their university buildings and move westwards; therefore, many HE institutions are now forced to substitute face-to-face teaching with web-based distance education or online education, often on a large scale, but within a short space of time and with limited resources.

Such an abrupt change can bring about numerous strategic managerial problems that require diligent handling, including the management of distance education, technical infrastructure, the design and 
development of electronic content, as well as the readiness of students and faculty members for teaching and learning online at a distance. While technical infrastructure (i.e., internet access, servers with Learning Management System) often sufficiently exists, know-how about conducting teaching online and respective faculty development is often lacking. Faculty members need to be integral to the design and development of e-content, and equally important, they have to improve their competencies as educators in order to be able to efficiently transfer teaching methods and techniques they use in traditional face-to-face classroom teaching into this new online learning environment.

\section{Contextualization}

e-Tutor was developed, and adapted to respond to this very vital need for the professional development of faculty members to teach online. Originally developed at Ankara University's Distance Learning Centre in Turkey, e-Tutor was adapted within the framework of a project funded by the Swiss National Science Foundation (SNSF) to support qualifying university staff in teaching online as an Open Educational Resource published under Creative Commons License. The program is accessible at www.etutor.academy, and available in three languages (English, Ukrainian ${ }^{1}$, and Russian ${ }^{2}$ ). This field note introduces e-Tutor from both national and international perspectives, along with its genesis, initial experiences, target group, aims and general concept, as well as its ongoing development.

The program was developed by Yasemin Gülbahar (Ankara University) in 2011, and updated in 2014. Meanwhile, it was adopted by another Turkish public university (Muğla Sitkı Koçman University) in 2012, which authorised it as a compulsory professional development activity for all faculty members who wished to teach online. Ankara and Muğla universities have since trained and certified more than 600 faculty members and educators from different levels as e-tutors since 2012. It was recently adopted by another Turkish public university in 2015. The potential of e-Tutor to allow for scaling effects was discussed by Rapp and Gülbahar (2016).

e-Tutor is comprised of 14 modules, each covering a different aspect of teaching online deemed relevant to the must-have competencies of online instructors. Each module uses a wide range of materials in order to ensure engagement of learners: handouts, narrated presentations, narrated videos, audios, interactive activities, e-portfolio artefacts, and other resources on the Web. The 14 modules are as follows:

1. Fundamentals of e-Learning: Basic Concepts, Types of e-Learning, Time vs. Place Asynchronous vs. Synchronous, e-Facilitator (changing roles and responsibilities), Learning Environments, Interaction Types.

2. Online Learning Theories: Behaviorism, Cognitivism, Constructivism, Connectivism, Adult Learning, Self-Regulated Learning. prepared the Ukrainian language version of e-Tutor based on the English original.

2 The Russian version of e-Tutor was produced by two other participants of the project: State Engineering University Armenia and Voronezh State University (Russia), also based on the English version. 
3. Learning and Content Management Systems: Online Learning Communities, e-Moderation, Learning Management Systems (LMS)/Content Management System (CMS) Features, Moodle, Massive Open Online Courses (MOOCs).

4. Managing Virtual Classrooms: Virtual Learning Environments and Web Conferencing Solutions for Webinars.

5. Online Instructional Design: Knowledge Management, Learning Goals and Outcomes, Instructional Design Models, Instructional Planning/Syllabus, Learning Opportunities/Activities, Course Structure.

6. Online Instructional Methods: Presentation, Training, Concept Teaching, Collaborative Learning, Problem-based and Project-based Learning, Discussion.

7. Copyright, Digital Rights Management (DRM), and Plagiarism: Copyright, DRM, Creative Commons, Plagiarism, Open Educational Resource (OER) and Massive Open Online Courses (MOOCs).

8. e-Assessment: Classical Assessment Approaches (tests, essays, matching, fill-in-the-blank, etc.), Alternative Assessment Approaches (webquest, e-portfolio, etc.)

9. Graphical Design: Graphical Design Principles, Graphical Organizers, Storyboarding.

10. Creating Effective Visuals: Posters, Mind Maps, Concept Maps, Infographics.

11. Multimedia Content Development: Audio-Visual Content, Narrated Presentations, Educational Videos.

12. Creating Interactive Applications: Tools for Creating Interactive Application, Interactive Mobile Applications.

13. Social Media and Emerging Technologies: Social Networking, Document Sharing, Media Sharing, Collaboration Tools, Blogs, and Microblogs.

14. Quality Control: Competencies, Usability, Course Evaluation, Satisfaction.

\section{Program Characteristics}

Although the program is accessible and available to all, it follows a train-the-trainer approach. Designed in a way to meet the needs of instructors of HE institutions who are to train their fellow colleagues in conducting teaching in blended or virtual teaching scenarios, the program (or parts of such as e-syllabus and materials) can be used by units or individuals in charge of faculty development in HE institutions (e.g., distance education or e-learning centers, in-service training departments, or other dedicated units) to train potential e-tutors on online teaching. The program is very user-friendly and structured so that experienced educators of faculty development programs may easily become acquainted with it. Or, what is preferable and considered the most ideal is that educators may initially participate in the program as learners and subsequently go on to be trainers of e-Tutor. 
This is, in fact, one of the main concepts behind e-Tutor. Online tutors as online learners beforehand. We consider it to be a useful experience to be an online-learner prior to becoming an online tutor. Taking part in e-Tutor as a learner provides potential online tutors with the opportunity to experience "the other side of the screen" before conducting training for their fellow colleagues or their students. In this way, they can reflect upon the experiences as online-learners and derive conclusions for their own subsequent instruction. On the other hand, for end-users of the program, potential e-tutors, we foresee the following initial scenario as being most likely: Many of the instructors taking e-Tutor already have experience in teaching face-to-face classes and already have the respective course materials (e.g., syllabuses, reading lists, presentations, course notes) prepared. All they want to do (or are requested, or as in the case of Ukraine, sometimes forced ${ }^{3}$ ) is to adapt their conventional, face-to-face teaching to the blended or fully online learning environments. Teaching experience may vary significantly, and the same concern is valid for explicit knowledge in the area of instructional design, and therefore, for e-Tutor, instructional design concepts, aspects are dealt with in some detail.

The second concept is that e-Tutor is based on a hands-on approach. This is the main assessment approach used in the program. Participants are expected to create their own e-course as a project, i.e., preparing syllabus, designing the course, preparing course materials, and integrating them into an LMS. They may choose from courses they currently teach face-to-face, or they may create a new course for teaching online in the future. Then, each session will end with an assignment related to the topic of that session, which forms an integrated part of their project work (e.g., writing syllabus, choosing teaching methods, and designing assignments). After uploading their work to the LMS, they receive feedback on the developed artefacts. The aim here is to ensure that, by the end of the program, the participants will be ready and confident to start their own online classes with a sound course design and instructional materials, which have already been checked, feedback provided, and improved as appropriate throughout the program. We consider it particularly important that participants have the confidence to cope with the requirements or problems experienced by instructors new to teaching online. During eTutor, they will have the opportunity to test, to experience, and learn to cope with potential problems comfortably, as well as to discuss possible solutions.

Consequently, we can speak of the aims of e-Tutor as an OER as twofold: (1) to ensure that participants of e-Tutor finish the program with a (by-and-large), complete online course they are confident in conducting; and (2) to provide HE institutions with an established concept and ready materials for faculty development in terms of planning and conducting distance learning. The latter aim has a limitation though: e-Tutor is aimed at a micro-level approach, which supports qualifying staff to become online educators; yet, it does not address a macro-level of faculty development which implements a total faculty development scheme in the area of e-learning.

The international identity of e-Tutor is owed to cooperation between Ankara University (Turkey) and Zurich University of Applied Sciences (Switzerland), developed over the course of two projects, both with Eastern European partners: "SoMeCat" (Social Media as a Catalyser for Cross-National Learning) dealing with the application of social media for teaching and learning, EU funded, and "Institutional Partnership: Implementing state-of-the-art didactics/ methods and research tools in academic teaching" dealing with improving various aspects of teaching in Eastern Europe, funded within the Eastern European Scopes budget line of the Swiss National Science Foundation. Since 2012, Ukrainian universities are highly recommended to introduce e-learning as a modern supplement to sometimes old-

3 Often there is substantial resistance to switching from accustomed face-to-face teaching to online teaching. e-Tutor addresses some of the fear-related obstacles but cannot change, for example, institutional incentive structures. 
fashioned correspondence education. This process was reinforced in 2014 as the result of adoption of a new law on education that created a legal background for e-learning. However, limited support has been given to implement these changes. Based on cooperation with Eastern European partners in the aforementioned projects, e-Tutor has been considered as an ideal solution to overcome the potential problems of faculty development in this issue. As a result, e-Tutor was translated into English in 2014, and implemented during the autumn semester of 2014 by two authors of this note. A total of 51 individuals participated in the program, mainly from Eastern Europe, but also from Norway, UK, and Canada. Due to the already busy agenda of the participants, the program was conducted as 14 modules, but completed in just a seven-week period. The program was then translated into Ukrainian and Russian by partners of the SNSF project. e-Tutor was then made available on Moodle in three languages: www.etutor.academy.

The SNSF project coordinator was approached by a delegation from Lughansk University (Eastern Ukraine) in July 2015, being informed that as the university buildings needed to be vacated and that they were being forced to conduct education virtually on a large scale, which posed particular challenges in qualifying/supporting staff for teaching online. It was then decided to apply for a small fund at SNSF in order to implement e-Tutor via the Eastern European project members, Ukraine's KROK University being the leader. The program commenced in October 2015 with 150 active participants. SNSF partners at KROK were already using e-Tutor for staff development in the area of distance learning. While much of the material can be used without local adaptation, some customization was deemed necessary, particularly in the area of assessment, and in order to match specific governmental regulations.

After completion of the first round of e-Tutor in Ukraine, a conference took place in Kiev in March 2016 in order to discuss the experiences from the course and to determine any necessary adaptations. These ensuing changes were implemented in May 2016. With the Ukraine finding itself in a challenging situation, it is our hope that e-Tutor will make a small contribution to mitigating the negative effects, particularly in terms of helping students who, after all, still deserve a proper education as their ticket to a better future.

\section{Conclusion}

e-Tutor started in Turkey as a local program in Turkish, and was then translated into English as a base language for translation to other languages; a valuable intermediate step for our project in Eastern Europe. Our ultimate aim is to further develop e-Tutor, and to make it available to other audiences that would like to start initiatives in the area of e-learning or blended learning, or to improve existing practices. We would appreciate your feedback on e-Tutor, how you have learned from it, and how to improve it. We would like to encourage you to let us know about resources ${ }^{4} /$ initiatives in similar areas, in particular if available in Russian or Ukrainian language, in order that we may consider providing links on the e-Tutor website and to create a small repository for the online learning community.

$4 \quad$ For instance, the Armenian partner, Information Security and Software Development Department at National Polytechnic University of Armenia (NPUA), developed an openly accessible manual in the Russian language on using cost-free cloud-based services for educational purposes. 


\section{References}

Rapp, C., \& Gülbahar, Y. (2016). e-Tutor: Scaling Staff Development in the Area of e-Learning

Competences. In Proceedings of the Third ACM Conference on Learning@ Scale, (pp.327328). ACM.

\section{Athabasca}

University

(c) 